Imágenes en biomedicina

\title{
Inmunorreacción de la infección por el virus de Zika en retina de ratones
}

Jorge Rivera1, Aura C. Rengifo', Gerardo Santamaría1', Sheryll Corchuelo², Diego Álvarez-Díaz ${ }^{1,3}$, Edgar Parra ${ }^{4}$, Julián Naizaque ${ }^{1}$, Jeison Monroy-Gómez ${ }^{1,5}$, Orlando Torres-Fernández ${ }^{1}$

${ }^{1}$ Grupo de Morfología Celular, Dirección de Investigación en Salud Pública, Instituto Nacional de Salud, Bogotá, D.C., Colombia

2 Vysnova Partners Inc., Bogotá, D.C., Colombia

${ }^{3}$ Grupo de Virología, Dirección de Redes en Salud Pública, Instituto Nacional de Salud, Bogotá, D.C., Colombia

${ }^{4}$ Grupo de Patología, Dirección de Redes en Salud Pública, Instituto Nacional de Salud, Bogotá, D.C., Colombia

${ }^{5}$ Departamento de Ciencias Básicas, Institución Universitaria Escuela Colombiana de Rehabilitación, Bogotá, D.C., Colombia

Recibido: 06/03/18

Aceptado: $20 / 02 / 19$

Publicado: 20/02/19

Citación:

Rivera J, Rengifo AC, Santamaría G, Corchuelo S, Álvarez DA, Parra EA, et al. Inmunorreacción de la infección por el virus de Zika en retina de ratones. Biomédica. 2019;39(Supl.2):8-10.

https://doi.org/10.7705/biomedica.v39i4.4402

\section{Correspondencia:}

Orlando Torres-Fernández, Grupo de Morfología Celular, Dirección de Investigación en Salud Pública, Instituto Nacional de Salud, Avenida Calle 26 № 51 20, Bogotá, D.C., Colombia

Teléfono: (571) 220 7700, extensión 1262 otorresf@ins.gov.co

Contribución de los autores:

Jorge Rivera: diseño del experimento, selección del tejido y procesamiento para inmunohistoquímica análisis de resultados y escritura del manuscrito Orlando Torres-Fernández, Aura C. Rengifo: diseño del experimento, análisis de resultados y revisión final del manuscrito

Gerardo Santamaría: inoculación y manejo de los animales, seguimiento de los signos de la enfermedad y procesamiento de muestras para la inclusión en parafina

Sheryll Corchuelo: procesamiento de muestras para el estudio inmunohistoquímico

Diego A. Álvarez-Díaz: diseño del experimento, purificación del aislamiento viral y determinación del título Edgar Parra: estudio histopatológico mediante microscopía de luz convencional Julián Naizaque: manejo de animales, seguimiento de los signos de la enfermedad en los ratones inoculados y en los de control

Jeison Monroy-Gómez: manejo y sacrificio de los animales, y obtención de los tejidos para el estudio histológico

Financiación:

Este trabajo fue financiado con recursos del

Departamento Administrativo de Ciencia, Tecnología e Innovación (Colciencias) y el Instituto Nacional de Salud (Colombia), proyecto "Estudio del efecto de la infección por virus Zika sobre la citomorfología, la neurobioquímica y el neurodesarrollo en modelos in vivo e in vitro", código 210474455818 , contrato № 672 de 2017.

\section{Conflicto de intereses:}

Los autores declaramos que no existen conflictos de intereses.
Las infecciones por el virus del Zika en humanos fueron esporádicas durante medio siglo antes de surgir en el Pacífico y en las Américas (1); la infección en humanos causaba apenas manifestaciones clínicas leves, semejantes a las de una gripa. Sin embargo, en los últimos años se ha demostrado que el virus del Zika puede causar enfermedades graves, entre ellas, la falla orgánica múltiple, la trombocitopenia y la púrpura trombocitopénica (2).

Asimismo, debido a su relación con anomalías en el desarrollo fetal, la infección congénita con este virus se ha denominado el "síndrome congénito del Zika" (3), el cual se caracteriza por microcefalia grave con cráneo parcialmente colapsado, cortezas cerebrales delgadas con calcificaciones subcorticales, cicatrices maculares y manchas pigmentarias retinianas focales, contracturas congénitas, hipertonía temprana acentuada y síntomas de afectación extrapiramidal (4). Los factores que han contribuido a la diseminación global del virus y al surgimiento y el cambio en el fenotipo, aún se desconocen.

El virus del Zika es un agente patógeno arboviral del género Flavivirus, familia Flaviviridae; tiene tres genotipos basados en las relaciones filogenéticas (África occidental, África oriental y Asia) y está estrechamente relacionado con el serocomplejo Spondweni $(5,6)$. A diferencia de otros flavivirus, como el virus del Nilo occidental y el virus de la encefalitis japonesa, cuyas infecciones en ratones C57BL/6 producen signos principales similares a los de estas enfermedades, el virus del Zika no produce los signos propios de la enfermedad en modelos animales de infección, como ratones $\mathrm{C} 57 \mathrm{BI} / 6 \mathrm{~J}$, ratas del algodón, cobayos, conejos y ratones CD1 $(7,8)$.

En algunos modelos experimentales con ratones se ha podido establecer que el virus infecta y lesiona preferentemente las células progenitoras neuronales, lo cual puede explicar su habilidad para deteriorar el desarrollo fetal del cerebro, y causar microcefalia y otros daños durante el neurodesarrollo.

Recientemente, se han reportado hallazgos histopatológicos oculares en fetos de humanos con diagnóstico de síndrome congénito de Zika fallecidos durante la gestación. Los rasgos más significativos fueron pérdida del epitelio pigmentario retinal, adelgazamiento de la coroides y atrofia parcial del nervio óptico (9). Además, se ha demostrado que el virus puede infectar las capas internas de la retina, causando coriorretinitis y muerte celular (10-12); dichos hallazgos coincidirían con los reportes de conjuntivitis y uveítis en los pacientes infectados $(1,13)$. 
En la figura 1 se ilustra la infección con el virus del Zika en la retina de un ratón $B A L B / c$ lactante de 10 días de edad después de haber sido inoculado por vía intracerebral con 6,8 × 104 unidades formadoras de placas (PFU).

El animal fue inoculado en el día 1 después del nacimiento. La inmunorreacción de los antígenos virales se localizó principalmente en la capa plexiforme interna, un área donde se forman numerosas conexiones sinápticas entre las células bipolares, las amacrinas y las ganglionares (14).
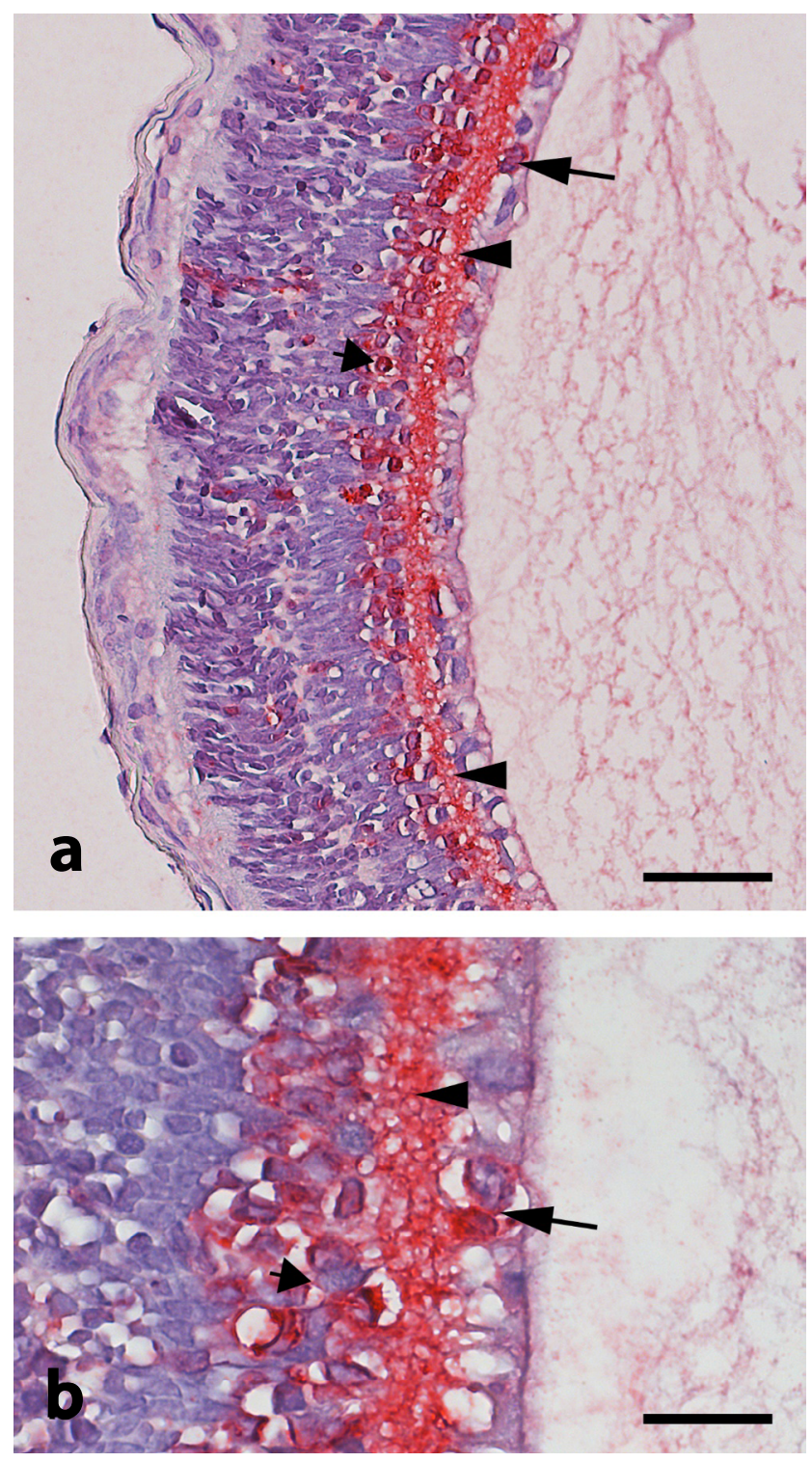

Figura 1. a) Corte antero-posterior del ojo que exhibe infección por el virus del Zika en la retina de ratón BALB/c. Se observa inmunorreacción principalmente en la capa plexiforme interna (puntas de flecha), en la capa nuclear interna y en algunas células ganglionares (flechas). No se evidencian alteraciones morfológicas evidentes en ninguna de las capas del ojo (esclerótica, coroides y retina).

b) En la imagen amplificada se destaca la presencia del antígeno viral en el pericarion de algunas células, en la capa nuclear interna y en la de una célula ganglionar.

Inmunohistoquímica por el método de fosfatasa alcalina; anticuerpo usado: anti-ZIKV policlonal dilución 1:1.000, donado por los Centers for Disease Control and Prevention (CDC), lote 6 1576, derivado de fluido ascítico hiperinmune de ratón. Contratinción con hematoxilina de Harris.

Barras: $50 \mu \mathrm{m}$ (a) y $20 \mu \mathrm{m}$ (b) 
La inmunotinción también fue evidente en el pericarion de las células de la capa nuclear interna y en el soma de algunas células ganglionares, que son las neuronas de proyección que dan origen a los axones del nervio óptico. Estos resultados concuerdan con el neurotropismo característico del virus del Zika en el modelo de ratón.

\section{Referencias}

1. Musso D, Gubler DJ. Zika virus. Clin Microbiol Rev. 2016;29:487-524. https://doi.org/10.1128/CMR.00072-15

2. Swaminathan S, Schlaberg R, Lewis J, Hanson KE, Couturier MR. Fatal Zika virus infection with secondary nonsexual transmission. N Engl J Med. 2016;375:1907-9. https://doi.org/10.1056/NEJMc1610613

3. Miranda-Filho D de B, Martelli CM, Ximenes RA, Araujo TV, Rocha MA, Ramos RC, et al. Initial description of the presumed congenital Zika syndrome. Am J Public Health. 2016;106:598-600. https://doi.org/10.2105/AJPH.2016.303115

4. Moore CA, Staples JE, Dobyns WB, Pessoa A, Ventura CV, Fonseca EB, et al. Characterizing the pattern of anomalies in congenital Zika syndrome for pediatric clinicians. JAMA Pediatr. 2017;171:288-95. https://doi.org/10.1001/jamapediatrics.2016.3982

5. Kuno G, Chang GJ, Tsuchiya KR, Karabatsos N, Cropp CB. Phylogeny of the genus Flavivirus. J Virol. 1998;72:73-83.

6. Lanciotti RS, Kosoy OL, Laven JJ, Vélez JO, Lambert AJ, Johnson AJ, et al. Genetic and serologic properties of Zika virus associated with an epidemic, Yap State, Micronesia, 2007. Emerg Infect Dis. 2008;14:1232-9. https://doi.org/10.3201/eid1408.080287

7. Rossi SL, Tesh RB, Azar SR, Muruato AE, Hanley KA, Auguste AJ, et al. Characterization of a novel murine model to study Zika virus. Am J Trop Med Hyg. 2016;94:1362-9. https://doi.org/10.4269/ajtmh.16-0111

8. Dick GW. Zika virus. Pathogenicity and physical properties. Trans R Soc Trop Med Hyg. 1952;46:521-34. https://doi.org/10.1016/0035-9203(52)90043-6

9. Fernández MP, Parra-Saad E, Ospina-Martínez M, Corchuelo S, Mercado-Reyes M, Herrera MJ, et al. Ocular histopathology features of congenital Zika syndrome. JAMA Ophthalmol. 2017;135:1163-9. https://doi.org/10.1001/jamaophthalmol.2017.3595

10. Singh PK, Guest JM, Kanwar M, Boss J, Gao N, Juzych MS, et al. Zika virus infects cells lining the blood-retinal barrier and causes chorioretinal atrophy in mouse eyes. JCI Insight. 2017;2:e92340. https://doi.org/10.1172/jci.insight.92340

11. Zhao Z, Yang M, Azar SR, Soong L, Weaver SC, Sun J, et al. Viral retinopathy in experimental models of Zika infection. Invest Ophthalmol Vis Sci. 2017;58:4355-65. https://doi.org/10.1167/iovs.17-22016

12. de Paula Freitas B, de Oliveira Dias JR, Prazeres J, Sacramento GA, Ko Al, Maia M, et al. Ocular findings in infants with microcephaly associated with presumed Zika virus congenital infection in Salvador, Brazil. JAMA Ophthalmol. 2016;134:529-35. https://doi.org/10.1001/jamaophthalmol.2016.0267

13. Furtado JM, Espósito DL, Klein TM, Teixeira-Pinto T, da Fonseca BA. Uveitis associated with Zika virus infection. N Engl J Med. 2016;375:394-6. https://doi.org/10.1056/NEJMc1603618

14. Wu SM. Synaptic organization of the vertebrate retina: General principles and speciesspecific variations: The friedenwald lecture. Invest Ophthalmol Vis Sci. 2010;51:1264-74. https://doi.org/10.1167/iovs.09-4396 